Full length article

\title{
The biopolymer produced by Rhizobium viscosum CECT 908 is a promising agent for application in microbial enhanced oil recovery
}

\author{
Márcia R. Couto, Eduardo J. Gudiña*, Débora Ferreira, José A. Teixeira, Lígia R. Rodrigues \\ CEB - Centre of Biological Engineering, University of Minho, 4710-057 Braga, Portugal
}

\section{A R T I C L E I N F O}

\section{Keywords:}

Microbial enhanced oil recovery

Polymer flooding

Xanthan gum

Rhizobium viscosum

Rheology

Apparent viscosity

\begin{abstract}
A B S T R A C T
Polymer flooding is one of the most promising techniques used to increase the productivity of mature oil reservoirs. Polymers reduce the mobility ratio of the injected water relative to the crude oil, improving the displacement of the entrapped oil and consequently, increasing oil recovery. Biopolymers such as xanthan gum have emerged as environmentally friendly alternatives to the chemical polymers commonly employed by the oil industry. However, in order to seek more efficient biomolecules, alternative biopolymers must be studied. Here, the applicability of a biopolymer produced by Rhizobium viscosum CECT 908 in Microbial Enhanced Oil Recovery (MEOR) was evaluated. This biopolymer exhibited better rheological properties (including higher viscosity) when compared with xanthan gum. Its stability at high shear rates (up to $300 \mathrm{~s}^{-1}$ ), temperatures (up to $80{ }^{\circ} \mathrm{C}$ ) and salinities (up to $200 \mathrm{~g} / \mathrm{L}$ of $\mathrm{NaCl}$ ) was also demonstrated. The biopolymer exhibited better performance than xanthan gum in oil recovery assays performed with a heavy crude oil, achieving $25.7 \pm 0.5 \%$ of additional recovery. Thus the $R$. viscosum CECT 908 biopolymer is a promising candidate for application in MEOR.
\end{abstract}

\section{Introduction}

Extracting the maximum amount of crude oil from the reservoirs is a major challenge for the oil industry and requires the application of tertiary oil recovery techniques, also known as enhanced oil recovery (EOR). Among the different EOR strategies, polymer flooding is one of the most promising due to its relative low cost when compared with other processes $[1,2]$.

During oil recovery operations, water is usually injected into the reservoirs in order to mobilize the entrapped oil. However, due to its low viscosity, water moves faster in the reservoir compared with crude oil. As a result, an irregular oil displacing front is formed, which results in water penetrating the oil front, leaving behind regions of unswept oil [3]. Water-soluble polymers are used to increase the viscosity of the injected water, reducing the mobility ratio of water relative to crude oil inside the reservoir; this results in the formation of a uniform oil displacement front, facilitating the mobilization of the residual oil and improving the overall sweep efficiency of water flooding. Several studies (including laboratory and field assays) demonstrated that polymer flooding can increase oil recovery by $20 \%$ over water flooding [3-7].

There are several aspects to be taken into account when selecting a polymer for application in EOR. It must be stable under the oil reservoir conditions (salinity, pressure and temperature), as well as at high shear rates, in order to maintain performance. The viscosity of a polymer solution is directly related to its molecular weight, and a higher viscosity of the displacing phase usually results in a higher oil recovery. However, if the molecular weight is too high, the polymer may plug the formation, thus lowering the flow and reducing the efficiency of polymer flooding. In addition, high molecular weight polymers are usually more susceptible to degradation at high shear rates [3]. Typical polymers used in EOR exhibit a shear-thinning or pseudoplastic behaviour; consequently, they exhibit low viscosities near the wellbore region due to the high flow rate (which results in high shear rates), which facilitates their injectivity. Once distant from the point of injection, as the shear rate decreases, their viscosity increases favouring the displacement of the residual oil $[5,6,8]$.

Synthetic polymers such as partially hydrolysed polyacrylamide (HPAM) have been widely used in polymer-based EOR due to their relative low cost. However, some of these synthetic polymers are hazardous to the environment due to the toxicity of certain compounds resulting from their degradation (e.g. acrylamides) [3,9-12]. Moreover, in some cases their application is limited by their instability at the oil

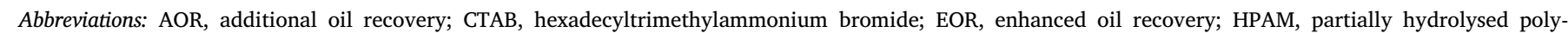

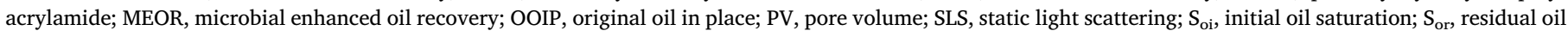
saturation; $\mathrm{S}_{\text {orpf }}$, oil recovered after polymer flooding; $\mathrm{S}_{\text {orwf }}$, oil recovered after water flooding

* Corresponding author at: CEB - Centre of Biological Engineering, University of Minho, Campus de Gualtar, $4710-057$ Braga, Portugal.

E-mail address: egudina@deb.uminho.pt (E.J. Gudiña). 
reservoir conditions. For instance, the viscosity of HPAM solutions is considerably reduced at high salinities and temperatures, and high shear rates result in the degradation of the polymer [13,14]. Due to the high flexibility of HPAM chains in aqueous solutions, they begin to fold irreversibly, particularly at high temperatures and high salinities, resulting in a significant loss of viscosity [14]. For that reason, the use of biopolymers produced by different microorganisms to increase oil recovery in mature reservoirs is currently receiving more interest worldwide, as part of a process known as microbial enhanced oil recovery (MEOR). MEOR, which uses microorganisms and their metabolites to recover additional oil from mature reservoirs, represents a promising strategy to replace the chemical compounds currently used in chemical enhanced oil recovery (CEOR), and its application and potential have been widely documented [1,15-19].

A variety of microorganisms produce biopolymers useful for application in MEOR, including species belonging to the genera Alcaligenes, Aureobasidium, Bacillus, Leuconostoc, Pseudomonas, Sphingomonas and Xanthomonas [1,4,12,20-24]. Among these biopolymers, xanthan gum, produced by the bacterium Xanthomonas campestris, stands out. Its production, structure, composition and rheological properties have been extensively studied and its application in MEOR, due to its ability to increase the viscosity of the injected water at low concentrations, resistance to shear stress, as well as temperature and salt tolerance, has been demonstrated in a wide range of oil field assays [1,25-27]. However, xanthan is more susceptible to microbial degradation and more expensive compared with the synthetic polyacrylamides, which can limit its application [3]. Consequently, it is necessary to screen and study new biopolymers with improved properties for application in MEOR.

Here, the biopolymer produced by Rhizobium viscosum CECT 908 was studied in respect of its potential application in MEOR for the first time. The molecular weight of this biopolymer was determined by static light scattering and its rheological properties were compared with those of xanthan gum. Finally, its ability to recover crude oil from sand-pack columns was evaluated using two different oils.

\section{Material and methods}

\section{Biopolymer production}

The strain $R$. viscosum CECT 908 (previously classified as Arthrobacter viscosus CECT 908 [28]), was used for biopolymer production. The composition of the culture medium used was: glucose $20 \mathrm{~g} / \mathrm{L}$; peptone $5 \mathrm{~g} / \mathrm{L}$; malt extract $3 \mathrm{~g} / \mathrm{L}$; yeast extract $3 \mathrm{~g} / \mathrm{L}$; $\mathrm{pH} 7.0$ [29]. The strain was stored at $-80{ }^{\circ} \mathrm{C}$ in the same culture medium supplemented with glycerol $(15 \%, v / v)$. Erlenmeyer flasks $(500 \mathrm{~mL})$ containing $200 \mathrm{~mL}$ culture medium were inoculated with $1 \%$ of a pre-culture of $R$. viscosum CECT 908 and incubated at $30{ }^{\circ} \mathrm{C}$ and rotated at $150 \mathrm{rpm}$. Samples $(5 \mathrm{~mL})$ were collected every $24 \mathrm{~h}$ to evaluate biopolymer production, which was determined from the viscosity of the samples (as described below). The crude biopolymer was recovered from the samples through precipitation with hexadecyltrimethylammonium bromide (CTAB), as described in [30], resuspended in $5 \mathrm{~mL}$ of demineralised water and dried at $60^{\circ} \mathrm{C}$ for $24 \mathrm{~h}$. The amount of crude biopolymer was determined as dry weight and expressed as $\mathrm{g} / \mathrm{L}$ culture. The results are presented as the mean \pm standard deviation (SD) of triplicate experiments.

When biopolymer production was maximal, the crude biopolymer was recovered and subsequently purified as in [30]. The purified biopolymer was freeze-dried, weighed and stored at room temperature (RT).

\section{Rheological properties and stability}

The rheological properties of the R. viscosum CECT 908 biopolymer (culture broth samples and purified biopolymer) and xanthan gum
(Sigma-Aldrich Co., USA) were studied using a hybrid rheometer (Discovery HR1, TA Instruments, USA). Assays were performed at $40{ }^{\circ} \mathrm{C}$ using a cone-plate geometry (diameter $60 \mathrm{~mm}$; angle $2.006^{\circ}$; gap $0.064 \mathrm{~mm})$. The shear stress $(T, \mathrm{mPa})$ and apparent viscosity $(\eta, \mathrm{mPa} s)$ were measured at different shear rates $\left(0.1-300 \mathrm{~s}^{-1}\right)$ through three successive flow ramps $\left(0.1 \rightarrow 300 \mathrm{~s}^{-1} ; 300 \rightarrow 0.1 \mathrm{~s}^{-1} ; 0.1 \rightarrow 300 \mathrm{~s}^{-1}\right)$. Each sample was analysed in triplicate.

For application in MEOR and to maintain their efficiency in oil recovery, biopolymers must retain their properties unaltered for the sweep time under the reservoir conditions. In order to study the stability of the biopolymers over the time when subjected to shear rates representative of oil reservoirs, thixotropic studies were performed according to the methodology proposed in [12]. Purified R. viscosum CECT 908 biopolymer and xanthan gum (both at $2 \mathrm{~g} / \mathrm{L}$ ) were exposed to a constant shear rate $\left(7.3 \mathrm{~s}^{-1}\right)$ at $40{ }^{\circ} \mathrm{C}$ for $2 \mathrm{~h}$. The shear rate used was selected according to similar literature reports as being representative of oil reservoir conditions [4,9,12,31,32]. In order to prevent evaporation of the samples during the assays, their outer surface was covered with silicon oil. The shear stress and apparent viscosity were measured every $30 \mathrm{~s}$.

To study the stability of the biopolymer to high temperatures, samples from a culture of $R$. viscosum CECT 908 were incubated at $80^{\circ} \mathrm{C}, 90^{\circ} \mathrm{C}$ or $100^{\circ} \mathrm{C}$ for 1 and $2 \mathrm{~h}$. Subsequently, the apparent viscosity of the samples was measured as described above and compared with values obtained for a non-treated sample. The effect of salinity was studied by adding $\mathrm{NaCl}$ at different concentrations $(25,50,100,150$ and $200 \mathrm{~g} / \mathrm{L}$ ) to samples from a culture of $R$. viscosum CECT 908. The apparent viscosity of the samples was measured and compared with the values obtained without addition of $\mathrm{NaCl}$.

All measurements were performed in triplicate at $40{ }^{\circ} \mathrm{C}$. Samples were allowed to stabilize for $24 \mathrm{~h}$ before analysis to avoid the presence of bubbles.

\section{Molecular weight determination}

The freeze-dried biopolymer was dissolved in ultrapure water at different concentrations $(0.05,0.10,0.15$ and $0.20 \mathrm{~g} / \mathrm{L})$. The refractive indices of these solutions were measured using a refractometer (RX$9000 \alpha$, ATAGO, Japan), and according to the results obtained, the refractive index increment $(d n / d c)$, i.e. the change in the refractive index of a solution as a function of solute concentration, was determined to be $0.2000 \mathrm{~g} / \mathrm{mL}$. Subsequently, the same solutions were used to calculate the molecular weight of the purified biopolymer through static light scattering (SLS) using a Zetasizer Nano ZS (Malvern Instruments, UK), following the manufacturer's instructions. The assays were performed at $25^{\circ} \mathrm{C}$, and the scattering angle was $173^{\circ}$. The full protocol can be found at https://www.malvernpanalytical.com/en/learn/knowledgecenter/user-manuals/MAN0485EN.html

\section{Oil recovery assays using sand-pack columns}

The performance of the $R$. viscosum CECT 908 biopolymer in oil recovery was studied using sand-pack columns through an ex situ approach, as described by Gudiña and co-workers [17]. The assays were performed using two crude oil samples with different viscosities: CLB $\left(\eta_{40^{\circ} \mathrm{C}}=81 \pm 5 \mathrm{mPa}\right.$ at $\left.1.4 \mathrm{~s}^{-1}\right)$ and PTX-11 $\left(\eta_{40^{\circ} \mathrm{C}}=167 \pm 41 \mathrm{mPa}\right.$ $\mathrm{s}$ at $1.4 \mathrm{~s}^{-1}$ ). These oils were provided by PARTEX Oil and Gas (Lisbon, Portugal), and their viscosities determined using a hybrid rheometer (Discovery HR1, TA Instruments, USA) equipped with a cone-plate geometry (diameter $60 \mathrm{~mm}$; angle $2.006^{\circ}$; gap $0.064 \mathrm{~mm}$ ) at $40^{\circ} \mathrm{C}$.

The oil recovery assays were performed using vertically oriented acrylic columns with a volume of $280 \mathrm{~mL}$, at $40^{\circ} \mathrm{C}$ and a constant flow rate of $2 \mathrm{~mL} / \mathrm{min}$. The columns, provided with a sieve and cap fixed at the bottom, were tightly filled with sand previously sifted with a $0.45 \mathrm{~mm}$ sieve, and top sieves and caps, provided with rubber ' $\mathrm{O}$ ' rings to hermetically seal the columns, were fixed. The caps on both ends of 
the columns were provided with holes for the insertion of inlet and outlet tubes. First, the columns were flooded with demineralised water. The pore volume (PV in $\mathrm{mL}$ ) was calculated by measuring the volume of water required to saturate each column and the porosity (\%) was determined by dividing the PV by the total volume of the column. Crude oil was then injected into the columns and the original oil in place (OOIP in $\mathrm{mL}$ ) was calculated as the volume of crude retained by the columns. The initial oil saturation $\left(S_{o i}, \%\right)$ was calculated as:

$S_{o i}=(\mathrm{OOIP} / \mathrm{PV}) \times 100$

Subsequently, the columns were incubated at RT for $24 \mathrm{~h}$, and then flooded again with demineralised water to remove the excess of crude oil; this step continued until crude oil was no longer observed in the effluent. The amount of crude oil recovered (oil recovered after water flooding $\left(S_{\text {orwf }}\right.$ in $\left.\mathrm{mL}\right)$ ) was determined volumetrically, and the residual oil saturation $\left(S_{o r}, \%\right)$ was calculated as:

$S_{\text {or }}=\left(\left(\right.\right.$ OOIP $\left.-S_{\text {orwf }}\right) /$ OOIP $) \times 100$

$200 \mathrm{~mL}$ (approximately two pore volumes) of different biopolymer solutions prepared at different concentrations in demineralised water (or alternatively, cultures of $R$. viscosum CECT 908) were then injected into the columns, followed by $250 \mathrm{~mL}$ of demineralised water. The volume of crude oil recovered (oil recovered after polymer flooding $\left(S_{\text {orpf }}\right.$ in $\left.\mathrm{mL}\right)$ ) was measured, and the additional oil recovery (AOR, \%) was calculated as:

$A O R=\left(S_{\text {orpf }} /\left(\right.\right.$ OOIP $\left.\left.-S_{\text {orwf }}\right)\right) \times 100$

Control assays were performed under the same conditions by injecting $450 \mathrm{~mL}$ of demineralised water into the columns (i.e. without the injection of biopolymer solutions). All assays were performed in duplicate.

\section{Results}

Biopolymer production by $R$. viscosum CECT 908

The time course of biopolymer production by $R$. viscosum CECT 908 was evaluated in flask assays. The viscosity of the samples taken at different time intervals was measured, and the crude biopolymer produced was quantified. As seen in Fig. 1, the apparent viscosity of the culture medium exhibited a considerable increase after $48 \mathrm{~h}$ of growth (606 $\pm 34 \mathrm{mPa} \mathrm{s}$ ). Thereafter, it continued to increase, reaching a maximum of $739 \pm 30 \mathrm{mPa} \mathrm{s}$ after $96 \mathrm{~h}$. Subsequently, the viscosity

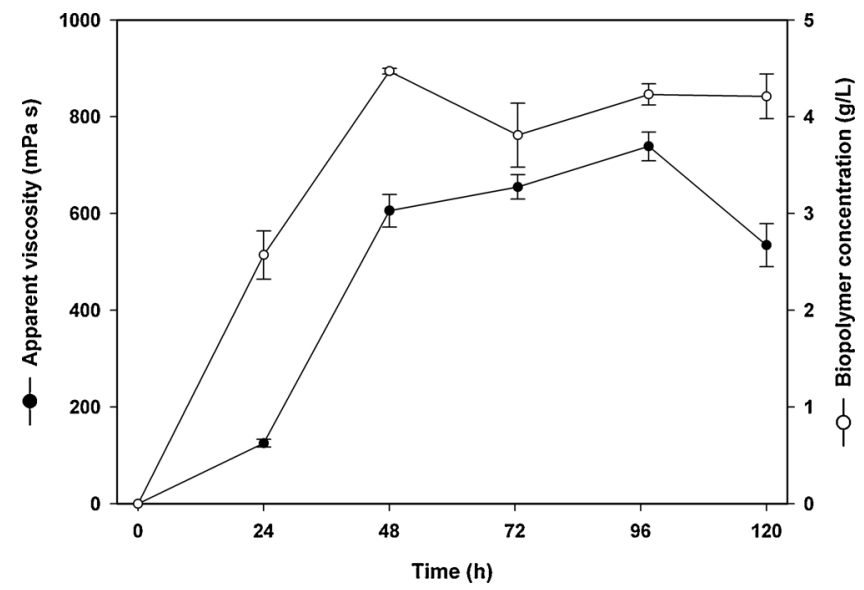

Fig. 1. Time course of apparent viscosity ( $\mathrm{mPa} s$ ) and crude biopolymer production $(\mathrm{g} / \mathrm{L}$ ) in assays performed with Rhizobium viscosum CECT 908 grown in flasks at $30{ }^{\circ} \mathrm{C}$ and $150 \mathrm{rpm}$. The apparent viscosity was measured at $40^{\circ} \mathrm{C}$ and the values correspond to a shear rate of $1.4 \mathrm{~s}^{-1}$. The results represent the average of two independent experiments \pm standard deviation.
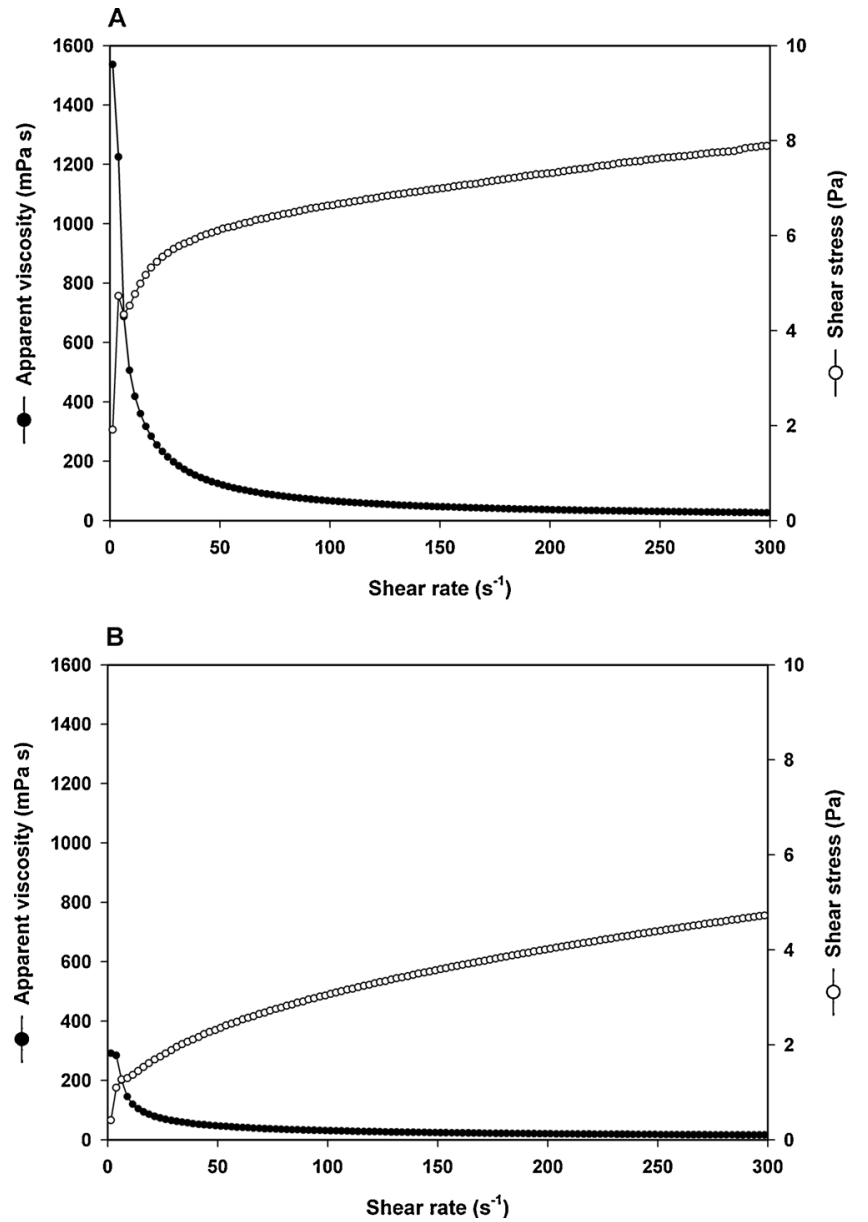

Fig. 2. Rheograms of aqueous solutions of the purified Rhizobium viscosum CECT 908 biopolymer (A) and xanthan gum (B) at a concentration of $2.5 \mathrm{~g} / \mathrm{L}$. The measurements were performed at $40^{\circ} \mathrm{C}$.

decreased, probably due to the degradation of the biopolymer. However, no direct relationship was observed between the viscosity of the culture medium and the amount of crude biopolymer produced, which achieved a maximum at $48 \mathrm{~h}(4.47 \pm 0.03 \mathrm{~g} / \mathrm{L})$, and then decreased slightly, possibly due to changes in the structure of the biopolymer over time, e.g. different degrees of polymerization, that ultimately resulted in an increase in its viscosity. The amount of crude biopolymer produced after $96 \mathrm{~h}(4.23 \pm 0.11 \mathrm{~g} / \mathrm{L})$ was equivalent to $2.0 \pm 0.1 \mathrm{~g} / \mathrm{L}$ of purified biopolymer.

The molecular weight of the biopolymer, determined through two independent SLS assays, was found to be $243.5 \pm 16.1 \mathrm{kDa}$ and the hydrodynamic diameter predicted was $28 \mathrm{~nm}$.

\section{Rheological properties}

\section{Flow curves}

The shear stress and apparent viscosity of aqueous solutions of the purified biopolymer and xanthan gum (both at $2.5 \mathrm{~g} / \mathrm{L}$ ) were measured over a wide range of shear rates $\left(0.1-300 \mathrm{~s}^{-1}\right)$ at $40{ }^{\circ} \mathrm{C}$ (Fig. $2 \mathrm{~A}, \mathrm{~B}$, respectively). In both cases the shear stress varied non-linearly with the shear rate, indicating that both biopolymers exhibited a non-Newtonian behaviour (i.e. the apparent viscosity is dependent on the shear rate). Furthermore, since the apparent viscosity decreased as the shear rate increased, they are pseudoplastics or shear-thinning fluids. The results demonstrated that both biopolymers were able to recover their properties immediately after being exposed to high shear rates $\left(300 \mathrm{~s}^{-1}\right)$, since the original viscosity values were recovered as the shear rate decreased; the flow curves obtained for both biopolymers in the three 
Table 1

Apparent viscosity values $\left(\eta_{40^{\circ} \mathrm{C}}\right)$ obtained for solutions of xanthan gum and the purified biopolymer produced by Rhizobium viscosum CECT 908 at different concentrations. The measurements were performed at $40{ }^{\circ} \mathrm{C}$, and the values correspond to a shear rate of $1.4 \mathrm{~s}^{-1}$. The results represent the average of three independent measurements \pm standard deviation.

\begin{tabular}{lll}
\hline & $\begin{array}{l}\text { Concentration } \\
(\mathrm{g} / \mathrm{L})\end{array}$ & $\eta_{40}{ }^{\circ} \mathrm{C}(\mathrm{mPa}$ s $)$ \\
\hline Biopolymer $\boldsymbol{R}$. viscosum CECT 908 & 1.0 & $194 \pm 8$ \\
& 2.5 & $1207 \pm 14$ \\
Xanthan gum & 3.0 & $1527 \pm 15$ \\
& 1.0 & $118 \pm 8$ \\
& 2.5 & $281 \pm 11$ \\
& 5.0 & $1159 \pm 79$ \\
\hline
\end{tabular}

successive flow ramps $\left(0.1 \rightarrow 300 \mathrm{~s}^{-1} ; 300 \rightarrow 0.1 \mathrm{~s}^{-1} ; 0.1 \rightarrow 300 \mathrm{~s}^{-1}\right)$ were coincident (data not shown). Furthermore, seen in Fig. 2, the $R$. viscosum CECT 908 biopolymer exhibited higher apparent viscosity values than xanthan gum at the same shear rate.

Subsequently, the rheological properties of both biopolymers were studied at different concentrations. Table 1 shows the apparent viscosity values obtained for the different biopolymer solutions at a shear rate of $1.4 \mathrm{~s}^{-1}$. The apparent viscosity of the R. viscosum CECT 908 biopolymer was always higher than that of xanthan gum at the same concentration.

Finally, the rheological behaviour of a $R$. viscosum culture, which contained an amount of biopolymer equivalent to about $2 \mathrm{~g} / \mathrm{L}$ of purified biopolymer, was studied. The profile obtained was similar to that exhibited by the purified biopolymer (Fig. 3), and the apparent viscosity at a shear rate of $1.4 \mathrm{~s}^{-1}$ was $601 \pm 21 \mathrm{mPa}$, which is in accordance with the viscosity values obtained for the solutions of purified biopolymer at the same range of concentrations.

\section{Stability at shear stress}

To study the stability of the $R$. viscosum CECT 908 biopolymer over the time when subjected to shear rates usually found in oil reservoirs, a real-time thixotropic assay was performed at a constant shear rate (7.3 $\left.\mathrm{s}^{-1}\right)$ and temperature $\left(40^{\circ} \mathrm{C}\right)$ for $2 \mathrm{~h}$. The variation of the shear stress and apparent viscosity over the shear time is presented in Fig. 4. It can be concluded that the structure of the biopolymer produced by $R$. viscosum CECT 908 was not affected by the shear rate applied for $2 \mathrm{~h}$, as the apparent viscosity remained constant. The same profile was observed for xanthan gum, although in this case the viscosity values were considerably lower.

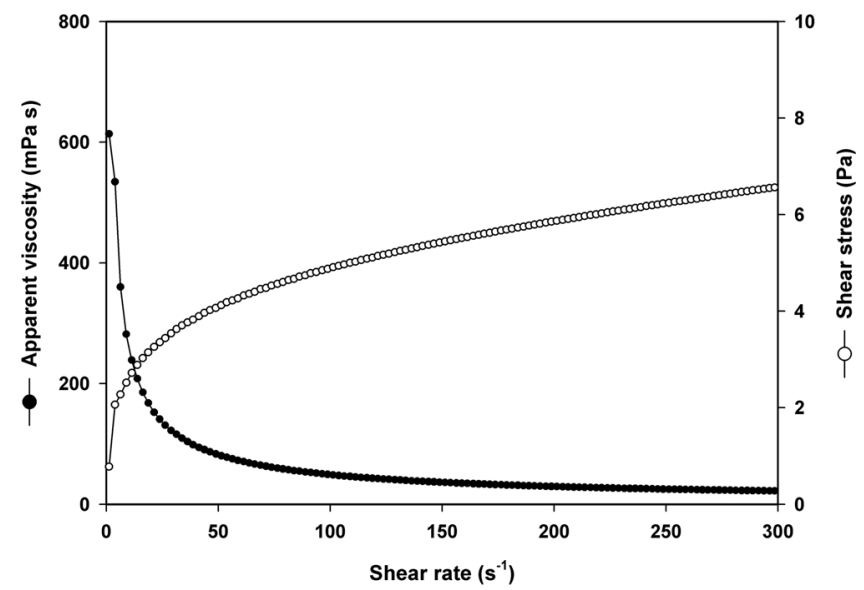

Fig. 3. Rheogram of a culture of Rhizobium viscosum CECT 908 grown in flask at $30{ }^{\circ} \mathrm{C}$ and $150 \mathrm{rpm}$. The measurements were performed at $40^{\circ} \mathrm{C}$.

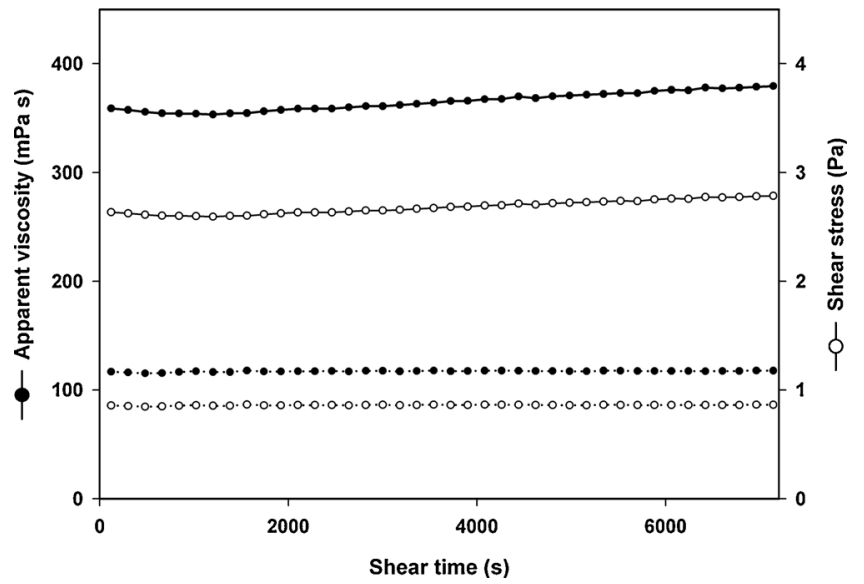

Fig. 4. Evolution of shear stress (mPa) and apparent viscosity (mPa s) over the shear time (s) of aqueous formulations of the purified Rhizobium viscosum CECT 908 biopolymer (continuous line) and xanthan gum (dotted line) at a concentration of $2 \mathrm{~g} / \mathrm{L}$. The experiments were performed at a constant shear rate of $7.3 \mathrm{~s}^{-1}$ and $40{ }^{\circ} \mathrm{C}$.

\section{Stability at high temperatures}

The effect of exposure of the biopolymer to high temperatures was studied. Culture broth samples were incubated at $80^{\circ} \mathrm{C}, 90^{\circ} \mathrm{C}$ and $100{ }^{\circ} \mathrm{C}$ for 1 and $2 \mathrm{~h}$, and the apparent viscosity measured. Treatments at $90{ }^{\circ} \mathrm{C}$ for 1 and $2 \mathrm{~h}$ led to decreased apparent viscosity of $12.5 \%$ and $23.6 \%$, respectively, whereas incubation at $100^{\circ} \mathrm{C}$ reduced viscosity by $13.6 \%$ and $20.6 \%$. However, incubations at $80^{\circ} \mathrm{C}$ for up to $2 \mathrm{~h}$ did not affect its viscosity.

\section{Stability at high salinities}

The effect of high salt concentrations on the rheological properties of $R$. viscosum CECT 908 biopolymer was also studied. $\mathrm{NaCl}$ at concentrations from 25 to $200 \mathrm{~g} / \mathrm{L}$ was added to culture broth samples. Subsequently, their apparent viscosity was measured and the values obtained were found to be similar to those for the culture broth without $\mathrm{NaCl}$. The performance of this biopolymer was unaffected by $\mathrm{NaCl}$ at concentrations as high as $200 \mathrm{~g} / \mathrm{L}$.

\section{Oil recovery assays}

R. viscosum CECT 908 biopolymer was evaluated for application in MEOR using sand-pack columns and an ex situ approach. Two different oils were used to evaluate the effect of the crude oil viscosity in the performance of the biopolymer: a light-medium oil (CLB, $\eta_{40^{\circ} \mathrm{C}}=81 \pm 5 \mathrm{mPa} \quad \mathrm{s}$ ) and a heavy oil (PTX-11, $\eta_{40^{\circ} \mathrm{C}}=167 \pm 41 \mathrm{mPa}$ s). The widely used xanthan gum was used as reference for comparison.

In the assays with the crude oil CLB, aqueous solutions of the purified biopolymer at $1 \mathrm{~g} / \mathrm{L}$ and the culture broth were evaluated (Table 2). A higher AOR (13.6 $\pm 0.9 \%)$ was obtained using the culture broth, which contained an amount of biopolymer equivalent to $2 \mathrm{~g} / \mathrm{L}$, compared to the purified biopolymer at $1 \mathrm{~g} / \mathrm{L}(\mathrm{AOR}=7.4 \pm 1.4 \%$ ). The purified biopolymer at $2 \mathrm{~g} / \mathrm{L}$ also resulted in a lower recovery (AOR $\approx 8 \%$, data not shown) compared to the culture broth. On the other hand, xanthan gum at $1 \mathrm{~g} / \mathrm{L}$ exhibited better performance (AOR $=27.7 \pm 5.0 \%$ ) compared to the $R$. viscosum CECT 908 biopolymer, although its viscosity was considerably lower (Table 1 ).

Due to the better performance exhibited by the culture broth of $R$. viscosum CECT 908 when compared with the purified biopolymer, only the culture broth was evaluated in the assays performed with the crude oil PTX-11 (Table 3). In this case, the $R$. viscosum biopolymer exhibited a higher displacement efficiency (AOR $=25.7 \pm 0.5 \%$ ) as compared to xanthan gum, even at a concentration of $2 \mathrm{~g} / \mathrm{L}(\mathrm{AOR}=19.8 \pm 1.2 \%)$. 
Table 2

Results obtained in MEOR sand-pack column assays performed with the crude oil CLB using the biopolymer produced by Rhizobium viscosum CECT 908 (purified biopolymer and culture broth) and xanthan gum. The AOR value is the corrected value obtained after subtracting the additional oil recovery obtained in the control assays. The results represent the average of two independent experiments \pm standard deviation.

\begin{tabular}{|c|c|c|c|}
\hline \multirow{3}{*}{$\begin{array}{l}\text { Oil Recovery } \\
\text { Parameters }\end{array}$} & \multicolumn{3}{|l|}{ Treatment } \\
\hline & \multicolumn{2}{|l|}{ Rhizobium viscosum } & \multirow{2}{*}{$\begin{array}{l}\text { Xanthan gum } \\
(1 \mathrm{~g} / \mathrm{L})\end{array}$} \\
\hline & $\begin{array}{l}\text { Purified biopolymer } \\
(1 \mathrm{~g} / \mathrm{L})\end{array}$ & Culture broth & \\
\hline $\mathrm{PV}(\mathrm{mL})$ & $91.0 \pm 4.2$ & $93.5 \pm 4.9$ & $85.0 \pm 3.6$ \\
\hline Porosity (\%) & $32.5 \pm 1.5$ & $33.4 \pm 1.8$ & $30.4 \pm 1.3$ \\
\hline OOIP (mL) & $72.6 \pm 2.3$ & $70.2 \pm 0.5$ & $73.8 \pm 1.9$ \\
\hline $\mathrm{S}_{\mathrm{oi}}(\%)$ & $80.0 \pm 6.3$ & $75.1 \pm 4.5$ & $86.8 \pm 5.2$ \\
\hline $\mathrm{S}_{\text {orwf }}(\mathrm{mL})$ & $47.3 \pm 0.4$ & $48.5 \pm 2.1$ & $42.5 \pm 1.5$ \\
\hline $\mathrm{S}_{\mathrm{or}}(\%)$ & $34.9 \pm 2.5$ & $30.9 \pm 3.5$ & $42.4 \pm 1.7$ \\
\hline $\mathrm{S}_{\text {orpf }}(\mathrm{mL})$ & $3.9 \pm 0.2$ & $5.1 \pm 0.9$ & $11.8 \pm 1.2$ \\
\hline AOR (\%) & $7.4 \pm 1.4$ & $13.6 \pm 0.9$ & $27.7 \pm 5.0$ \\
\hline
\end{tabular}

Table 3

Results obtained in MEOR sand-pack column assays performed with the crude oil PTX-11 using the biopolymer produced by Rhizobium viscosum CECT 908 (culture broth) and xanthan gum. The AOR value is the corrected value obtained after subtracting the additional oil recovery obtained in the control assays. The results represent the average of two independent experiments \pm standard deviation.

\begin{tabular}{llll}
\hline Oil Recovery Parameters & \multicolumn{3}{l}{ Treatment } \\
\cline { 2 - 4 } & $\begin{array}{l}\text { R. viscosum } \\
\text { (culture broth) }\end{array}$ & \multicolumn{2}{l}{ Xanthan gum } \\
\cline { 2 - 4 } & & $1 \mathrm{~g} / \mathrm{L}$ & $2 \mathrm{~g} / \mathrm{L}$ \\
\hline PV (mL) & $94.0 \pm 0.0$ & $94.0 \pm 0.0$ & $92.0 \pm 0.0$ \\
Porosity (\%) & $33.6 \pm 0.0$ & $33.6 \pm 0.0$ & $32.9 \pm 0.0$ \\
OOIP (mL) & $90.9 \pm 4.5$ & $85.3 \pm 4.0$ & $88.5 \pm 0.0$ \\
$\mathrm{~S}_{\text {oi }}(\%)$ & $96.7 \pm 4.9$ & $90.7 \pm 4.2$ & $96.2 \pm 0.0$ \\
$\mathrm{~S}_{\text {orwf }}(\mathrm{mL})$ & $50.1 \pm 2.8$ & $50.1 \pm 0.1$ & $50.1 \pm 0.1$ \\
$\mathrm{~S}_{\text {or }}(\%)$ & $44.9 \pm 0.2$ & $41.2 \pm 2.6$ & $43.4 \pm 0.1$ \\
$\mathrm{~S}_{\text {orpf }}(\mathrm{mL})$ & $15.6 \pm 1.3$ & $10.6 \pm 0.2$ & $12.5 \pm 0.6$ \\
AOR (\%) & $25.7 \pm 0.5$ & $17.6 \pm 1.8$ & $19.8 \pm 1.2$ \\
\hline
\end{tabular}

\section{Discussion}

R. viscosum CECT 908 produced $4.23 \pm 0.11 \mathrm{~g}$ of crude biopolymer per litre after $96 \mathrm{~h}$ of growth, which is in accordance with the results reported using the same strain but different culture media (3.3-5.0 g/L) $[29,33]$. Although the production of higher amounts of biopolymer by different microorganisms has been reported $(5-14 \mathrm{~g} / \mathrm{L})$, as can be seen from Table 4, in most of cases the viscosities obtained were similar or lower than those obtained for R. viscosum CECT 908. This indicates a higher efficiency of the biopolymer studied here, since higher viscosities were obtained at lower concentrations.
The efficiency of a (bio)polymer in EOR is highly dependent on its rheological properties and it is expected that a higher viscosity will result in a better performance. In order to characterize the rheological behaviour of the biopolymer studied here, the effect of shear rate on shear stress and the apparent viscosity was determined. The R. viscosum biopolymer exhibited a pseudoplastic or shear-thinning behaviour, as previously reported for other biopolymers such as xanthan gum, diutan gum and welan gum $[4,8,9,12,36,37]$. For this type of (bio)polymer, as the shear rate increases, the apparent viscosity decreases and the shear stress increases. A shear-thinning behaviour favours (bio)polymer application in EOR, because during their injection in the oil reservoir, they undergo high shear rates $\left(\geq 100 \mathrm{~s}^{-1}\right)$ in the near-wellbore region, which results in low viscosity values, improving their injectivity and preventing damage to the oil formation. Once transported away from the near-wellbore region, the shear rate experienced by the (bio) polymer solution is lower (about 1 to $10 \mathrm{~s}^{-1}$ ), allowing the recovery of high viscosity values, required for a favourable mobility control and, consequently, an efficient oil displacement $[9,13]$. However, the high shear rates achieved during the injection of the (bio)polymer solution can result in the mechanical breakdown of the molecules due to the high shear stress values achieved [3,14]. The results demonstrated that the $R$. viscosum biopolymer and xanthan gum were able to recover their properties immediately after being exposed to shear rates as high as 300 $\mathrm{s}^{-1}$. These results are in good agreement with previous studies reporting that biopolymers are more stable to mechanical degradation due to shear stress under real injection conditions compared to synthetic polymers such as HPAM [13].

For application in EOR, and in order to maintain their performance, (bio)polymers must retain their properties unaltered during the time of application under the reservoir conditions. The biopolymer produced by $R$. viscosum CECT 908 was not affected by exposure to a shear rate representative of the oil reservoir conditions $\left(7.3 \mathrm{~s}^{-1}\right)$ over time, in agreement with results obtained for other biopolymers [12].

Another limiting factor for the application of (bio)polymers in EOR is the high temperature commonly found in many oil reservoirs. The $R$. viscosum biopolymer remained stable up to $80^{\circ} \mathrm{C}$. Other biopolymers such as diutan gum, produced by Sphingomonas spp., or scleroglucan, produced by Sclerotium spp., remained stable up to $90-95^{\circ} \mathrm{C}[12,38]$. The viscosity of the biopolymer produced by Pseudomonas oleovorans was significantly reduced when exposed to $100^{\circ} \mathrm{C}$ for $1 \mathrm{~h}$, but was not affected by temperatures up to $80^{\circ} \mathrm{C}[36,39]$. In contrast, xanthan gum, welan gum and HPAM exhibited a considerable loss of viscosity between $75^{\circ} \mathrm{C}$ and $85^{\circ} \mathrm{C}[8,9,12,27]$.

Moreover, the rheological properties of the biopolymer were not affected by $\mathrm{NaCl}$ concentrations as high as $200 \mathrm{~g} / \mathrm{L}$. Other biopolymers such as xanthan gum, diutan gum and welan gum remained stable at salinities up to $100 \mathrm{~g} / \mathrm{L}[9,12,27]$. In contrast, the viscosity of the biopolymer produced by $P$. oleovorans was considerably reduced by $\mathrm{NaCl}$ at $100 \mathrm{~g} / \mathrm{L}$ [36]. For the synthetic polymer HPAM, the addition of $\mathrm{NaCl}$ at $9.5 \mathrm{~g} / \mathrm{L}$ reduced viscosity by $74 \%$ [12].

The molecular weight of biopolymers is highly dependent on the producing strain, the culture media and culture conditions used, as well

Table 4

Viscosity values and biopolymer yields reported for different microorganisms.

\begin{tabular}{|c|c|c|c|c|}
\hline Microorganism & [Biopolymer] (g/L) & $\begin{array}{l}\text { Viscosity } \\
\text { (mPa s) }\end{array}$ & Time (hours) & Reference \\
\hline Rhizobium viscosum & 4.2 & $739\left(40^{\circ} \mathrm{C}\right)$ & 96 & This study \\
\hline Rhizobium tropici & 5.5 & $50-70\left(25^{\circ} \mathrm{C}\right)$ & 96 & [34] \\
\hline Aureobasidium pullulans & 13 & $28-60\left(25^{\circ} \mathrm{C}\right)$ & 120 & [21] \\
\hline Bacillus licheniformis & 6.2 & $90\left(30^{\circ} \mathrm{C}\right)$ & 24 & [24] \\
\hline Bacillus licheniformis TT33 & 4.5 & $120\left(28^{\circ} \mathrm{C}\right)$ & 72 & {$[23]$} \\
\hline Schizophyllum commune & $\sim 5$ & $\sim 2000\left(25^{\circ} \mathrm{C}\right)$ & 312 & {$[22]$} \\
\hline Sphingomonas paucimobilis ATCC 31461 & 14 & $\sim 400\left(30^{\circ} \mathrm{C}\right)$ & 48 & [35] \\
\hline
\end{tabular}

The temperature at which the viscosity was measured is indicated and the fermentation time required to produce the biopolymer. 
Table 5

Summary of oil recovery studies performed with different biopolymers and HPAM.

\begin{tabular}{|c|c|c|c|c|c|c|}
\hline (Bio)polymer & Producer & [Polymer] (g/L) & $\eta$ polymer solution (mPa s) & $\eta$ oil (mPa s) & AOR (\%) & Reference \\
\hline \multirow[t]{2}{*}{-} & Rhizobium viscosum & 2.0 & $739\left(40^{\circ} \mathrm{C}\right)$ & $81\left(40^{\circ} \mathrm{C}\right)$ & $14\left(40^{\circ} \mathrm{C}\right)$ & This study \\
\hline & & 2.0 & $739\left(40^{\circ} \mathrm{C}\right)$ & $167\left(40^{\circ} \mathrm{C}\right)$ & $26\left(40^{\circ} \mathrm{C}\right)$ & \\
\hline \multirow[t]{5}{*}{ Xanthan gum } & Xanthomonas campestris & 1.0 & $118\left(40^{\circ} \mathrm{C}\right)$ & $81\left(40^{\circ} \mathrm{C}\right)$ & $28\left(40^{\circ} \mathrm{C}\right)$ & This study \\
\hline & & 2.0 & $202\left(40^{\circ} \mathrm{C}\right)$ & $167\left(40^{\circ} \mathrm{C}\right)$ & $20\left(40^{\circ} \mathrm{C}\right)$ & \\
\hline & & 1.75 & $\sim 200\left(75^{\circ} \mathrm{C}\right)$ & $274\left(90^{\circ} \mathrm{C}\right)$ & $14\left(75^{\circ} \mathrm{C}\right)$ & [12] \\
\hline & & & & & $9.3\left(90^{\circ} \mathrm{C}\right)$ & \\
\hline & & 1.75 & $\sim 600\left(25^{\circ} \mathrm{C}\right)$ & $458\left(50^{\circ} \mathrm{C}\right)$ & $18\left(50^{\circ} \mathrm{C}\right)$ & [4] \\
\hline \multirow[t]{2}{*}{ Diutan gum } & Sphingomonas sp. & 1.75 & $\sim 2500\left(75^{\circ} \mathrm{C}\right)$ & $274\left(90^{\circ} \mathrm{C}\right)$ & $25\left(75^{\circ} \mathrm{C}\right)$ & [12] \\
\hline & & & & & $21\left(90^{\circ} \mathrm{C}\right)$ & \\
\hline Welan gum & Alcaligenes sp. & 1.75 & $\sim 2000\left(25^{\circ} \mathrm{C}\right)$ & $458\left(50^{\circ} \mathrm{C}\right)$ & $25\left(50^{\circ} \mathrm{C}\right)$ & [4] \\
\hline Pullulan & Aureobasidium pullulans & $13.0^{*}$ & $28-60\left(25^{\circ} \mathrm{C}\right)$ & $20-25$ & $9.4\left(60^{\circ} \mathrm{C}\right)$ & [21] \\
\hline \multirow[t]{2}{*}{ Schizophyllan } & Schizophyllum commune & $5.4^{*}$ & $\sim 2000\left(25^{\circ} \mathrm{C}\right)$ & $2350\left(45^{\circ} \mathrm{C}\right)$ & $28\left(45^{\circ} \mathrm{C}\right)$ & [22] \\
\hline & & 1.0 & $\sim 500\left(55^{\circ} \mathrm{C}\right)$ & $35\left(55^{\circ} \mathrm{C}\right)$ & $10\left(55^{\circ} \mathrm{C}\right)$ & [40] \\
\hline- & Athelia sp. & 1.0 & $\sim 900\left(85^{\circ} \mathrm{C}\right)$ & $1050\left(85^{\circ} \mathrm{C}\right)$ & $14-18\left(85^{\circ} \mathrm{C}\right)$ & [41] \\
\hline \multirow[t]{2}{*}{ HPAM } & Synthetic & 1.0 & $\sim 38\left(45^{\circ} \mathrm{C}\right)$ & $34\left(50^{\circ} \mathrm{C}\right)$ & $14\left(45^{\circ} \mathrm{C}\right)$ & [11] \\
\hline & & 1.75 & $\sim 10\left(75^{\circ} \mathrm{C}\right)$ & $274\left(90^{\circ} \mathrm{C}\right)$ & $9.5\left(75^{\circ} \mathrm{C}\right)$ & [12] \\
\hline
\end{tabular}

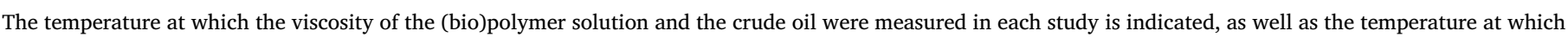
the oil recovery assay was performed.

* Crude biopolymer.

as the recovery process. The molecular weight calculated for the $R$. viscosum CECT 908 biopolymer $(243.5 \pm 16.1 \mathrm{kDa})$ is in the same range as those reported for scleroglucan or welan gum (100-700 kDa) $[4,9,38]$, but lower compared with those of diutan gum, levan, pullulan or xanthan gum $(1,000-50,000 \mathrm{kDa})[9,12,21]$. The rheological properties of polymers are affected by their structure and molecular weight. Usually, the viscosity of a polymer formulation increases with molecular weight, which can lead to a higher oil recovery. However, high molecular weight biopolymers are usually more susceptible to mechanical degradation due to shear stress, and their application exhibits limitations related with their injectivity and propagation through the reservoir [3].

The $R$. viscosum biopolymer exhibited a better performance than xanthan gum in oil recovery assays performed with a heavy crude oil. However, the same effect could not be observed with a light crude oil. This may be due to a more favourable mobility ratio between the injected biopolymer solution and the heavy crude oil (resulting in a more uniform displacement front). This represents an advantage for the application of the biopolymer studied here in EOR, as crude oils with high viscosities are more difficult to recover. Furthermore, the results demonstrate that the unpurified biopolymer (culture broth) exhibited a better performance in oil recovery compared to the purified biopolymer, probably due to the presence of synergistic metabolites. This is an advantage for application in MEOR, as it is not necessary to purify the biopolymer, which is expensive and laborious. Moreover, the $R$. viscosum biopolymer exhibited a similar or better performance in oil recovery as compared to other (bio)polymers, particularly the synthetic polymer HPAM, as can be seen in Table 5 .

The results obtained in the oil recovery assays performed with the $R$. viscosum CECT 908 biopolymer, together with its stability under high salinity, high temperature and high shear rates, make it a promising candidate for application in EOR. However, to make it competitive with synthetic polymers, it is necessary to reduce its production costs (since $R$. viscosum is strictly aerobic, the biopolymer should be produced $e x$ situ and subsequently injected into the oil well). This can be achieved through the use of agro-industrial wastes or by-products as substrates for its production and through the optimization of the fermentation process, as reported for other biopolymers [25,26,38].

\section{Declaration of interest}

None

\section{Acknowledgments}

This work was supported by PARTEX OIL AND GAS (Lisobon, Portugal). The authors acknowledge the Portuguese Foundation for Science and Technology (FCT) for financial support under the scope of the strategic funding of UID/BIO/04469/2013 unit and COMPETE 2020 (POCI-01-0145-FEDER-006684). The authors also acknowledge financial support from BioTecNorte operation (NORTE-01-0145FEDER-000004) and the project MultiBiorefinery (POCI-01-0145FEDER-016403) funded by the European Regional Development Fund under the scope of Norte2020 - Programa Operacional Regional do Norte. Márcia R. Couto was supported by the doctoral Grant SFRH/BD/ $132998 / 2017$ provided by FCT. Débora Ferreira is recipient of a fellowship (UMINHO/BD/21/2016) supported by a doctoral advanced training (call NORTE-69-2015-15) funded by the European Social Fund under the scope of Norte2020 - Programa Operacional Regional do Norte. E. J. Gudiña was supported by the Post-Doctoral grant UMINHO/ BPD/39/2015 from the project UID/BIO/04469/2013, funded by FCT.

\section{References}

[1] Patel J, Borgohain S, Kumar M, Rangarajan V, Somasundaran P, Sen R. Recent developments in microbial enhanced oil recovery. Renew Sustain Energy Rev 2015;52:1539-58. https://doi.org/10.1016/j.rser.2015.07.135.

[2] Gudiña EJ, Pereira JFB, Rodrigues LR, Coutinho JAP, Teixeira JA. Isolation and study of microorganisms from oil samples for application in Microbial enhanced Oil Recovery. Int Biodeterior Biodegrad 2012;68:56-64. https://doi.org/10.1016/j. ibiod.2012.01.001.

[3] Rellegadla S, Prajapat G, Agrawal A. Polymers for enhanced oil recovery: fundamentals and selection criteria. Appl Microbiol Biotechnol 2017;101(11):4387-402. https://doi.org/10.1007/s00253-017-8307-4.

[4] Xu L, Xu G, Yu L, Gong H, Dong M, Li Y. The displacement efficiency and rheology of welan gum for enhanced heavy oil recovery. Polym Adv Technol 2014;25(10):1122-9. https://doi.org/10.1002/pat.3364.

[5] Wever DAZ, Picchioni F, Broekhuis AA. Polymers for enhanced oil recovery: a paradigm for structure-property relationship in aqueous solution. Prog Polym Sci 2011;36(11):1558-628. https://doi.org/10.1016/j.progpolymsci.2011.05.006.

[6] Abidin AZ, Puspasari T, Nugroho WA. Polymers for enhanced oil recovery technology. Procedia Chem 2012;4:11-6. https://doi.org/10.1016/j.proche.2012.06. 002 .

[7] El-hoshoudy AN, Desouky SM. Synthesis and evaluation of acryloylated starch-gpoly (Acrylamide/Vinylmethacrylate/1-Vinyl-2-pyrrolidone) crosslinked termopolymer functionalized by dimethylphenylvinylsilane derivative as a novel polymerflooding agent. Int J Biol Macromol 2018;116:434-42. https://doi.org/10.1016/j. ijbiomac.2018.05.056.

[8] Xu L, Xu G, Liu T, Chen Y, Gong H. The comparison of rheological properties of aqueous welan gum and xanthan gum solutions. Carbohydr Polym 2013;92(1):516-22. https://doi.org/10.1016/j.carbpol.2012.09.082.

[9] Gao C. Potential of Welan gum to enhance oil recovery. J Pet Explor Prod Technol 2015;5(2):197-200. https://doi.org/10.1007/s13202-014-0135-9.

[10] Wu X, Xiong C, Xu H, Zhang J, Lu C, Lu X, et al. A novel particle-type polymer and 
IOR/EOR property evaluation. SPE-177421-MS. Abu Dhabi International Petroleum Exhibition and Conference 2015(November):9-12. https://doi.org/10.2118/ 177421-MS.

[11] Xu X, Ouyang J, Wang Y, Wang C. Experimental investigation using an acrylamidebased polymer with emulsifying capability for enhanced oil recovery: a preliminary study. J Ind Eng Chem 2017;55:110-8. https://doi.org/10.1016/j.jiec.2017.06. 034.

[12] Li Y, Xu L, Gong H, Ding B, Dong M, Li Y. A microbial exopolysaccharide produced by Sphingomonas species for enhanced heavy oil recovery at high temperature and high salinity. Energy Fuels 2017;31(4):3960-9. https://doi.org/10.1021/acs. energyfuels.6b02923.

[13] Romero-zerón L. Enhanced oil recovery methods. Chapter 10 In: Riazi MR, editor. MNL73: exploration and production of petroleum and natural gasUSA: ASTM International; 2016. p. 249-300. https://doi.org/10.1520/MNL7320140020. ISBN: 978-0-8031-7068-1.

[14] Zaitoun A, Makakou P, Blin N, Al-Maamari RS, A-AR Al-Hashmi, Abdel-Goad M. Shear stability of EOR polymers. Soc Pet Eng J 2012;17:335-9. https://doi.org/10. 2118/141113-PA. SPE-141113-PA.

[15] Sen R. Biotechnology in petroleum recovery: the microbial EOR. Prog Energy Combust Sci 2008;34(6):714-24. https://doi.org/10.1016/j.pecs.2008.05.001.

[16] Gao CH, Zekri A. Applications of microbial-enhanced oil recovery technology in the past decade. Energy Sources A Recovery Util Environ Eff 2011;33(10):972-89. https://doi.org/10.1080/15567030903330793.

[17] Gudiña EJ, Pereira JFB, Costa R, Coutinho JAP, Teixeira JA, Rodrigues LR Biosurfactant-producing and oil-degrading Bacillus subtilis strains enhance oil recovery in laboratory sand-pack columns. J Hazard Mater 2013;261:106-13. https:// doi.org/10.1016/j.jhazmat.2013.06.071.

[18] Bachmann RT, Johnson AC, Edyvean RGJ. Biotechnology in the petroleum industry: an overview. Int Biodeterior Biodegrad 2014;86:225-37. https://doi.org/10.1016/ j.ibiod.2013.09.011.

[19] Safdel M, Anbaz MA, Daryasafar A, Jamialahmadi M. Microbial enhanced oil recovery, a critical review on worldwide implemented field trials in different countries. Renew Sustain Energy Rev 2017;74:159-72. https://doi.org/10.1016/j.rser 2017.02.045.

[20] Soudmand-Asli A, Ayatollahi SS, Mohabatkar H, Zareie M, Shariatpanahi SF. The in situ microbial enhanced oil recovery in fractured porous media. J Pet Sci Eng 2007;58(1-2):161-72. https://doi.org/10.1016/j.petrol.2006.12.004.

[21] Elshafie A, Joshi SJ, Al-Wahaibi YM, Al-Bahry SN, Al-Bemani AS, Al-Hashmi A, et al. Isolation and characterization of biopolymer producing Omani Aureobasidium pullulans strains and its potential applications in microbial enhanced oil recovery. SPE-185326-MS. SPE Oil and Gas India Conference and Exhibition 2017(April):4-6. https://doi.org/10.2118/185326-MS.

[22] Joshi SJ, Al-Wahaibi YM, Al-Bahry S, Elshafie A, Al-Bemani AS, Al-Hashmi A, et al. Production and application of schizophyllan in microbial enhanced heavy oil recovery. SPE-179775-MS. SPE EOR Conference at Oil and Gas West Asia 2016(March):21-3. https://doi.org/10.2118/179775-MS. Muscat, Oman.

[23] Suthar H, Hingurao K, Desai A, Nerurkar A. Selective plugging strategy based microbial enhanced oil recovery using Bacillus licheniformis TT33. J Microbiol Biotechnol 2009;19(10):1230-7. https://doi.org/10.4014/jmb.0904.04043.

[24] Dhanarajan G, Rangarajan V, Bandi C, Dixit A, Das S, Ale K, et al. Biosurfactantbiopolymer driven microbial enhanced oil recovery (MEOR) and its optimization by an ANN-GA hybrid technique. J Biotechnol 2017;256:46-56. https://doi.org/10. 1016/j.jbiotec.2017.05.007.

[25] García-Ochoa F, Santos VE, Casas JÁ, Gómez E. Xanthan gum: production, recovery, and properties. Biotechnol Adv 2000;18(7):549-79. https://doi.org/10.1016/ S0734-9750(00)00050-1.
[26] Habibi H, Khosravi-Darani K. Effective variables on production and structure of xanthan gum and its food applications: a review. Biocatal Agric Biotechnol 2017;10:130-40. https://doi.org/10.1016/j.bcab.2017.02.013.

[27] Jang HY, Zhang K, Chon BH, Choi HJ. Enhanced oil recovery performance and viscosity characteristics of polysaccharide xanthan gum solution. J Ind Eng Chem 2015;21:741-5. https://doi.org/10.1016/j.jiec.2014.04.005.

[28] Flores-Félix JD, Ramírez-Bahena MH, Salazar S, Peix A, Velázquez E. Reclassification of Arthobacter viscosus as Rhizobium viscosum comb. nov. Int J Syst Evol Microbiol 2017;67:1789-92. https://doi.org/10.1099/ijsem.0.001864.

[29] Quintelas C, Silva VB, Silva B, Figueiredo H, Tavares T. Optimization of production of extracellular polymeric substances by Arthrobacter viscosus and their interaction with a 13X zeolite for the biosorption of $\mathrm{Cr}(\mathrm{VI})$. Environ Technol 2011;32(14):1541-9. https://doi.org/10.1080/09593330.2010.543930.

[30] Novak JS, Tanenbaum SW, Nakas JP. Heteropolysaccharide formation by Arthrobacter viscosus grown on xylose and xylose oligosaccharides. Appl Environ Microbiol 1992;58(11):3501-7http://aem.asm.org/content/58/11/3501.full.pdf.

[31] Kumar P, Raj R, Koduru N, Kumar S, Pandey A. Field implementation of mangala polymer flood: initial challenges, mitigation and management. SPE-179820-MS. SPE EOR Conference at Oil and Gas West Asia 2016(March):21-3. https://doi.org/ 10.2118/179820-MS. Muscat, Oman.

[32] Al-Hashmi R, Divers T, Al-Maamari RS, Favero C, Thomas A. Improving polymer flooding efficiency in Oman oil fields. SPE-179834-MS. SPE EOR Conference at Oil and Gas West Asia 2016(March):21-3. https://doi.org/10.2118/179834-MS. Muscat, Oman.

[33] López E, Ramos I, Sanromán MA. Extracellular polysaccharides production by Arthrobacter viscosus. J Food Eng 2003;60(4):463-7. https://doi.org/10.1016/ S0260-8774(03)00078-5.

[34] Castellane TCL, Campanharo JC, Colnago LA, Coutinho ID, Lopes EM, Lemos MVF, et al. Characterization of new exopolysaccharide production by Rhizobium tropici during growth on hydrocarbon substrate. Int J Biol Macromol 2017;96:361-9. https://doi.org/10.1016/j.ijbiomac.2016.11.123.

[35] Fialho AM, Martins LO, Donval Leitão JH, Ridout MJ, Jay AJ, Morris VJ, et al. Structures and properties of gellan polymers produced by Sphingomonas paucimobilis ATCC 31461 from lactose compared with those produced from glucose and from cheese whey. Appl Environ Microbiol 1999;65(6):2485-91.

[36] Freitas F, Alves VD, Carvalheira M, Costa N, Oliveira R, Reis MAM. Emulsifying behaviour and rheological properties of the extracellular polysaccharide produced by Pseudomonas oleovorans grown on glycerol byproduct. Carbohydr Polym 2009;78(3):549-56. https://doi.org/10.1016/j.carbpol.2009.05.016.

[37] Freitas F, Alves VD, Torres CAV, Cruz M, Sousa I, Melo MJ, et al. Fucose-containing exopolysaccharide produced by the newly isolated Enterobacter strain A47 DSM 23139. Carbohydr Polym 2011;83(1):159-65. https://doi.org/10.1016/j.carbpol. 2010.07.034

[38] Castillo NA, Valdez AL, Fariña JJI. Microbial production of scleroglucan and downstream processing. Front Microbiol 2015;6:1106. https://doi.org/10.3389/ fmicb.2015.01106.

[39] Alves VD, Freitas F, Costa N, Carvalheira M, Oliveira R, Gonçalves MP, et al. Effect of temperature on the dynamic and steady-shear rheology of a new microbial extracellular polysaccharide produced from glycerol byproduct. Carbohydr Polym 2010;79(4):981-8. https://doi.org/10.1016/j.carbpol.2009.10.026.

[40] Gao C. Application of a novel biopolymer to enhance oil recovery. J Petrol Explor Prod Technol 2016;6:749-53. https://doi.org/10.1007/s13202-015-0213-7.

[41] Xia W, Dong X, Zhang Y, Ma T. Biopolymer from marine Athelia and its application on heavy oil recovery in heterogeneous reservoir. Carbohydr Polym 2018;195:53-62. https://doi.org/10.1016/j.carbpol.2018.04.061. 